\title{
AQUILO QUE FLUI NO ÁMAGO DOS JAPONESES
}

Considerações sobre Jikkinshô

Motohiro Izumi

(Professor visitante na USP

março/84 - fevereiro/85)

Acredita-se que todo ser humano tenha um objetivo na vida. Há pessoas com grandes propósitos a se concretizarem no decorrer de suas vidas, e há aquelas com objetivos pequenos a serem atingidos em um futuro próximo. Mas, todo homem vive necessariamente com um objetivo. Além disso, qualquer ser humano, quando exerce alguma atividade social para atingir esse objetivo, passa a possuir um modus vivendi próprio, ou seja, uma maneira de proceder adequada para esse fim. Porém, isso poderá ser realizado de modo consciente ou não. $E$, também, poderão surgir grandes divergências dependendo dos costumes ou mesmo dos povos. De qualquer modo, é certo que as pessoas vivem com um objetivo. Se a maioria das pessoas participasse da vida social sem objetivos, a sociedade tornar-se-ia caótica, e, provavelmente, a ordem social seria perturbada.

Mas, será que haveria momentos em que a maior parte das pessoas perdesse o objetivo para viver? Quando se pensa em que tipo de circunstâncias tal situação pudesse ocorrer, pode-se citar o momento em que há uma brusca mudança na forma de governo de um país após sua derrota em uma guerra (como, por exemplo, quando da transição de uma sociedade capitalista para uma comunista). Ainda que essa mudança não seja completa na estrutura política, é inevitável que esta 
situação ocorra após a derrota em uma guerra. Aliás, tal situação coincide com aquela do Japão imediatamente após a derrota na Segunda Guerra Mundial. Com efeito, o povo passou por momentos de inquietude ao indagar sobre o seu futuro e o destino do país, pois os objetivos de vida haviam sido perdidos. Comparando-se a época da derrota com a atual situação do Japão, observa-se um estado de restabelecimento que nos chama a atenção. Será que haveria nos japoneses algo em comum, para que o Japão pudesse ter prosperado até o estado atual? Gostaria, então, de refletir, aqui, acerca do que flui no âmago dos japoneses.

A Segunda Guerra Mundial envolveu praticamente todos os países do mundo. Em contrapartida, acredita-se que o primeiro conflito que envolveu todo o Japão, tenha sido a lu ta entre os clãs de Genji e Heike (século XII). Até então, o Japão mantinha uma política cujo poder estava centralizado no imperador. Mas Genji vence essa batalha, e os samurais passam a governar o Japão, o que representou uma experiência inédita para o povo. Assim, em função desse conflito, a estrutura de governo acabou mudando completamente. Supõe-se que o sentimento das pessoas daquela época tenha sido semelhante àquele experimentado pelos japoneses quando da derrota na Segunda Guerra Mundial. Presume-se que as pessoas tenham se sentido inquietas com a perda de objetivos e do modo de viver. Quando esse tipo de situação perdurava, durante o século XIII, surge um livro - Jikkinshó (Dez Ensinamentos Escolhidos) - que orientava como o homem deveria proceder. Gostaria, então, de refletir, com base nesta obra, sobre este modus vivendi comum do homem que continua a existir na alma dos japoneses, pois acredita-se que, embora os tempos tenham mudado e a ciência desenvolvido, aquilo que existe na alma dos homens ainda permanece inalterável.

A época da composição do Jikkinshô está claramente indicada no prefácio, onde se lê que "foi conclu fdo em outubro de 1252" Há três versões a respeito do autor. Entretanto, não se sabe exatamente quem tenha sido. Em função do prefácio, sabe-se apenas que foi uma pessoa idosa que desejava o seu bem-estar pessoal após a morte.

Jikkinshô é uma obra que pertence ao campo de setsuwabungaku (literatura de contos e lendas). Setsuwasho (livro de contos e lendas) é 
uma coletânea de episódios tidos pelo autor como interessantes e memoráveis, anotados e compilados, que, posteriormente, foram organizados segundo a intenção literária do autor. Assim, neste tipo de literatura é relevante, também, observar a relação seqüencial entre os contos.

Pode-se apreender o objetivo da composição do Jikkinshô e também a razão de sua denominação, logo nas primeiras linhas do prefácio:

"Como os seres humanos têm muitos trabalhos neste mundo, a tendência é de que as pessoas inteligentes tenham maiores chances de obter sucesso, e as pessoas ignorantes de acabar no fracasso, quaisquer que sejam suas posições sociais. Assim, tomando como subsídio vários episódios que li ou ouvi de pessoas, extraí alguns, ora retratando sucessos, ora fracassos, incentivando com os primeiros e precavendo com os últimos as pessoas jovens e inexperientes, para que, com isso, elas venham a conhecer um modus vivendi ideal. Denominei-o Jikkinshô porque o dividi em dez artigos; e, além disso, ordenei-os em três volumes, de modo a torná-lo um livro de cabeceira"

Deste modo, percebe-se que Jikkinshó foi elaborado para ensinar como o homem deve viver a sua vida.

Os dez artigos estão estruturados da seguinte forma:

Parte 1 - conceder benefícios às pessoas;

Parte 2 - deixar de ser arrogante;

Parte 3 - não menosprezar as pessoas;

Parte 4 - não intervir na vida alheia;

Parte 5-escolher os amigos;

Parte 6 - ser honesto e fiel;

Parte 7 - ser cauteloso nas decisões a tomar;

Parte 8 - saber suportar e tolerar diversas situações;

Parte 9 - saber controlar os desejos;

Parte 10 - desejar a arte e o ofício, o saber e a sagacidade.

Desta divisão, as partes de 1 a 4 , de 5 a 7 , e de 8 a 10 correspondem, respectivamente, aos volumes 1,11 e 111 do Jikkinshô. 0 autor inclui várias histórias tidas como interessantes, que leu ou ouviu de terceiros, agrupando-as em cada um dos dez artigos. Além disso, no 
início de cada parte, o autor deixa claro o seu propósito, ou seja, na parte 1, por exemplo, antes de relatar as várias histórias, 0 autor faz um resumo daquilo que pretende transmitir. Através do entendimento desses resumos, presume-se que se consiga compreender aproximadamente aquilo que o autor pretendia. A partir deste momento, gostaria de fazer uma análise, tendo como ponto básico tais resumos. Como se trata de setsuwasho (livro de contos e lendas), tentarei analisar levando também em consideração a ligação da parte $1 \mathrm{com}$ a parte 2, da parte 2 com a 3 e assim sucessivamente.

\section{III}

A parte 1 tem como centro as seguintes máximas: "as pessoas que estão no topo do Estado não devem fazer distinção das demais, ainda que estas sejam tolas"; "essas pessoas devem oferecer benefícios de maneira igual e justa para todos"; "devem procurar reconhecer as qualidades do próximo e não censurá-lo logo no primeiro erro"; "em relação aos homens que traem os outros não há necessidade de conceder-lhes benefícios"; "há necessidade de proteger aqueles cujas faculdades mentais são inferiores desde o nascimento" Aqui são relacionadas as atitudes e concepções desejáveis às pessoas que conduzem o Estado, isto é, tais pessoas não devem fazer distinções entre os próximos, relacionando-se com espírito aberto, igual e imparcialmente. $E$, o que deve ser observado aqui é que os homens são todos iguais, mas em relação às pessoas de faculdades mentais inferiores há a necessidade de protegê-las, e não igualá-las.

Analisando-se o resumo da parte 1, sob o ponto de vista de sua relação com as demais partes, nota-se que não há uma ligação explícita pois a parte 1 é uma exposição das atitudes das pessoas que governam - Estado, e as demais se referem à preparação das pessoas que têm como intenção atingir o ponto máximo de uma determinada área da sociedade. Porém, numa análise global, observa-se que da parte 2 em diante o autor determina, como fator ideal, atingir o topo, qualquer que seja o campo. Entretanto, reunindo os diversos níveis da sociedade, o objeto máximo vem a ser na realidade o Estado. Portanto, considerando-se que 0 autor colocou em primeiro plano a pessoa que fica no topo do Estado, a parte 1 não está em desarmonia com as demais. Pode-se afirmar que a parte 1 e as demais estão numa relação Intima e que o equilíbrio geral do Jikkinshó é mantido. 
A parte 2 afirma que "em todos os seres humanos, a arrogância tende a despontar, e são poucas as pessoas que possuem espírito modesto" Há pessoas que "não discernem sua posição", "não dão ouvidos às opiniões alheias, convencendo-se de que suas idéias são mais importantes", "procedem de maneira estranha à sua época" "não se adaptam ao ambiente", "são ricas em conhecimento, e por possuírem talento passam a desprezar os outros", "interessam-se apenas por coisas que estão ligadas a si mesmas e acreditam que isso é o melhor" Tais pessoas são assim "porque são fúteis e porque existe no fundo de suas almas um sentimento de arrogância" $E$ diz também que "não se deve agir egocentricamente, e sim, dando atenção aos próximos, acompanhando-os e sendo sensível aos costumes do seu meio" O preceito básico da parte 2 mostra que se deve deixar de lado o sentimento de arrogância, fazendo uso da reflexão e tomando uma atitude harmoniosa em relação aos costumes da sociedade.

A parte 3 afirma que o ser humano tem a tendência de desprezar os indivíduos "pobres" "de posição social inferior", "com habilidade inferior", "decadentes", "órfãos", "viúvas", etc.; mas "isto é uma atitude das pessoas tolas" e, abordando pessoas com desprezo, tendem a dizer o que não deveriam, e à medida que procedem no que não se deve, acabam recebendo o seu castigo, em forma de humilhação" Há uma continuidade entre as partes 2 e 3, pois o item 3 diz que, devido ao sentimento de arrogância, as pessoas acabam por desprezar as outras.

A parte 4 afirma que "não se deve falar inescrupulosamente com as pessoas, repreendê-las por seus defeitos, revelar segredos ou fazer perguntas inoportunas com as quais elas possam se sentir constrangidas", pois "as pessoas deixarão de se relacionar abertamente com aquele que for considerado um elemento loquaz" Isto demonstra que as pessoas que procedem de modo incorreto o fazem porque desprezam as outras. Tem-se, assim, a continuidade entre as partes 3 e 4. Por fim, o autor afirma que "no que concerne à vida alheia, deve-se proceder levando-se em consideração o sentimento de outrem"

A parte 5 afirma que "deve-se desejar encontrar bons amigos", pois o homem é fácil de ser influenciado pelo meio em que vive, e o autor pensa que o amigo ideal é "aquele que realmente se comunica com o coraçâo" A continuidade entre as partes 4 e 5 está na parte 4 , no ponto onde se diz que "as pessoas deixarão de se relacionar abertamente com aquele que for considerado um elemento loquaz" $E$ o autor considera que tudo aquilo que não deve ser feito, tal como foi 
citado nas partes 2, 3 e 4, depende apenas da prudência do indivíduo, isto é, o autor deixa claro que o fator primordial das partes 2, 3 e 4 está no sentimento do indivíduo. Percebe-se, assim, que o autor expôs as partes 2, 3 e 4 levando em consideração a parte 5 . Tentando resumir, aqui, nota-se que as partes 2, 3, 4 e 5 tratam do relacionamento humano, que não pode ser menosprezado na vida do homem em sociedade. Ele afirma, portanto, que o mais importante nesse relacionamento é o sentimento do indivíduo.

A parte 6 argumenta que "submeter-se cegamente a um senhor não significa ser verdadeiramente fiel, e, também, que obedecer cegamente aos pais não significa ser realmente um bom filho; discutir quando for preciso e obedecer quando o outro estiver correto corresponde realmente a ser fiel e bom filho" No entanto, o autor também diz que, "como regra básica da sociedade humana, discordar daquilo que uma pessoa está decidida a fazer é algo malquisto, e concordar passa a ser benquisto", e "aquele que reprova algum defeito do seu senhor fica em desvantagem para receber benefícios deste" Explica, dessa forma, que na vida em sociedade há a necessidade de uma flexibilidade no poder de raciocínio e de julgamento, e que as coisas não devem ser conduzidas apenas em função de uma argumentação rígida, mas sim tentar compreender o sentimento genuíno e comum ao ser humano. $O$ autor também fala da cautela necessária em se proceder a uma advertência, observando que "deve-se advertir com cautela, de forma a não ser maldoso em relação ao outro, e, também, para não ser malquisto", e que "é preciso advertir gentilmente, avaliando o sentimento do outro naquele instante" Porém, afirma que "em relação à pessoa em quem se confia, deve-se evitar 0 arrependimento posterior por não ter procedido à advertência, e que, quando houver necessidade de advertir, não se deve ser maldoso com relação à pessoa"

A mensagem, portanto, é de que, em situações onde a advertência à pessoa em quem se deposita grande confiança é realmente necessária (situações de "vida ou morte" por exemplo), deve ser feita sem se preocupar com o fato de se tornar benquisto ou não.

Observa-se, desta forma, que na parte 6 o autor deseja enfatizar especificamente a necessidade de se voltar para o senso comum da sociedade em que se vive, tentando alcançar sua compreensão (assimilação), visto que não se pode viver ignorando aquilo que é denominado sociedade, pois o homem não vive sozinho.

0 elo de ligação da parte 5 com a parte 6 está em que o mais importante no relacionamento das pessoas é a comunicação mútua 
do espírito do homem, assim como a parte 5 afirma que o amigo verdadeiro é aquele com quem realmente o sentimento se comunica. Pode-se, assim, afirmar que há ligação entre as partes 5 e 6 , pois a parte 6 toma este sentimento humano como regra geral da sociedade.

A parte 7 afirma que "não se deve apegar ao desejo único de obter conforto", que "desejär bons resultados sem qualquer esforço é algo totalmente inaceitável" e que "quando se possui um desejo forte e específico numa determinada área, deve-se lutar para torná-la real", ou seja, o autor demonstra que o homem deve se esforçar rumo a um objetivo e procurar atingí-lo. Ele incentiva "desde jovem a servir ao senhor, reconhecer seus erros e tornar-se independente", "seguir o ofício da família" E, quanto aos casos de mera sorte ou de sucessos sem esforço, estes são rejeitados, pois "tais exemplos são raros, não devendo ser levados em consideração" 0 autor afirma ainda que "nada se faz a não ser com seu próprio discernimento", e que, para isso, "deve-se dar vazão à análise de várias possibilidades em relação a qualquer assunto"

0 caráter de inter-relação entre as partes 6 e 7 está no ponto em que ambas as partes tratam do sentimento humano, sendo que a parte 7 trata da necessidade de se possuir um espírito suficientemente forte para vencer as "doces" e inverossímeis seduções, tão comuns na caminhada humana rumo a um objetivo. Cabe notar aqui que a parte 6 difere da parte 7 pelo fato de a parte 6 tratar do espírito do homem em função do relacionamento pessoal, enquanto que a parte 7 fala do mesmo sentimento, não do ponto de vista do relacionamento pessoal, mas quanto à força de vontade da pessoa ao nível individual.

A parte 8 afirma que "saber tolerar é uma qualidade realmente admirável no homem", que "na vida há muitas amarguras, mas deve tolerá-las para vencer neste mundo", e, ainda, que "os jovens devem suportar a fome nas horas em que não há alimento suficiente, aprendendo, com isso, a viver; devem suportar o frio na falta de abrigo, pois, mesmo na servidão, devem procurar o caminho para sua independência. Enfim, deve-se tolerar e suportar qualquer que seja a situação" Em síntese, quando o homem se empenha rumo a um objetivo, ele se depara com várias situações difíceis, mas é preciso suportá-las e tolerá-las.

Para tolerar e suportar é necessário na pessoa uma força de vontade muito forte. Portanto, pode-se afirmar que há um inter-relacionamento entre as partes 7 e 8 , no sentido de que em ambas a maior ênfase é colocada no espírito individual da pessoa (desejo forte). Cabe 
notar, também, que a parte 8 está ligada à parte 7 no ponto em que se incentiva a caminhar em direção ao objetivo (independência).

A parte 9 sustenta que "não se deve ter ódio de uma pessoa imprudentemente nos momentos de discórdia", e que "mesmo que uma pessoa infrinja a razão humana, ou deixe de cumprir a palavra, deve-se tolerá-la sem perder a calma e tentar imaginar um motivo justo para tal procedimento. Desta maneira, chega-se a uma compreensão, ou até mesmo a um sentimento de culpa, pela sua própria ira inicial" Enfim, a mensagem é de que se deve controlar suas emoções, mesmo nos momentos de discórdia ou de incompreensão.

A inter-relação das partes 8 e 9 se verifica nos fatores de tolerância e perseverança.

A parte 10 afirma que "é natural as pessoas que nasceram numa família, tradicionalmente vinculada a alguma especialidade, possuírem dons específicos, mas mesmo sem terem nascido com tal privilégio, qualquer indivíduo possui, necessariamente, alguma habilidade. Há aqueles que, embora tenham nascido numa família ligada a alguma especialidade, não a seguem por não terem se esforçado. Todos os homens devem se esforçar ou para se tornar especialista em uma determinada área ou para seguir a profissão especifica de sua famflia, pois independentemente de sua origem pode-se tornar especialistas de acordo com sua capacidade", isto é, deve-se esforçar para ser reconhecido no mundo a que aspirou, desenvolvendo sua capacidade rumo ao objetivo. Acredita-se que 0 autor quis dar ênfase principalmente no que diz respeito ao esforço pessoal...E, quanto à ênfase dada à "sucessão do ofício da família", pode-se tratar de um relato sobre a degradação do nivel dos profissionais nas diversas áreas específicas daquela época.

Não há um elo de ligação entre as partes 9 e 10. No entanto, a parte 10 é de extraordinária importância por ser o último item, presumindo-se, portanto, que esta sua localização seja produto de uma profunda reflexão por parte do autor. Além disso, trata-se, sem dúvida, de um item para o qual o autor teria desejado maior relevância. Assim, supöe-se que, através do desligamento deste item com o anterior, o autor tivesse tido a intenção de dar maior destaque à parte 10.

\section{IV}

Tentarei agora resumir aquilo que o autor qu is dizer em Jikkinshô. 
Ele afirma que a prioridade máxima na vida de um homem é ter um objetivo sólido, e ter clara consciência disso (partes 7.8 e 10), devendo viver com discernimento, acumulando esforços para sua concretização (partes 7 e 10). Para tanto, considera como base primordial o sentimento da pessoa (partes 4 e 5).

Quando se esforça rumo a um objetivo é natural que se depare com dificuldades, mas é preciso suportá-las (parte 8), e, também, é natural que se depare com várias conversas sedutoras, mas é preciso proceder com prudência e cautela (parte 7). Caminhar rumo a um objetivo não é um ato passível de ser realizado, senão dentro de uma estrutura chamada sociedade humana, sendo, por isso, necessário estar também de acordo com os hábitos da sociedade (partes 2 e 6). Além disso, o relacionamento humano também torna-se algo relevante, pois o homem precisa participar da vida social. No relacionamento humano, certamente, há coisas que não se realizam conforme a vontade, mas é preciso não perder a calma e ser prudente (parte 9). Quando um indivíduo se torna superior às outras pessoas, o espírito arrogante tende a despontar (parte 2), passando então a desprezá-las (parte 3) ou a interferir nas suas vidas e, conseqüentemente, as pessoas deixarão de manter um relacionamento aberto com este indivíduo (parte 4). E realmente lamentável na vida em sociedade, não ter com quem se relacionar abertamente (alguém para confiar). E, assim, o autor, como fator sumamente importante no relacionamento humano, cita a necessidade de se relacionar abertamente com uma determinada pessoa, ou seja, ter um verdadeiro amigo (parte 5). Até aqui, refere-se às pessoas em geral, mas com relação aos governantes, o autor torna claro que estes devem se relacionar com as pessoas de forma igual e imparcial, além da necessidade de terem uma atitude tolerante (parte 1). Analisando-se desta forma, percebe-se que estes preceitos têm por base o pensamento de que $o$ indivíduo existe em função da sociedade e vice-versa.

Acredita-se que este tipo de visão da vida ainda continue presente no espírito do povo japonês, ou seja, existe uma plena consciència do valor do sentimento, e, baseando nisto, o povo japonês se direciona rumo à concretização dos seus objetivos, procurando novos caminhos e respeitando o relacionamento humano e os costumes da sociedade. Esta visão da vida representa, portanto, o alicerce da grande potência econômica que é o Japão de hoje. 